\title{
Structural characterization of unusually stable polycyclic ozonides
}

\author{
R.C. Cusati ${ }^{\text {a }}$, U.A. Pereira ${ }^{a}$, L.C.A. Barbosa ${ }^{\mathrm{a}, \mathrm{b}, *}$, C.R.A. Maltha ${ }^{\mathrm{a}}$, José W.M. Carneiro ${ }^{\mathrm{c}}$, R.S. Corrêa ${ }^{\mathrm{d}}$, \\ A.C. Doriguetto ${ }^{\mathrm{e}}$ \\ ${ }^{a}$ Department of Chemistry, Federal University of Viçosa, Av. P.H. Rolfs, CEP 36570-000 Viçosa, MG, Brazil \\ ${ }^{b}$ Department of Chemistry, ICEx, Universidade Federal de Minas Gerais, Av. Pres. Antônio Carlos, 6627, Campus Pampulha, CEP $31270-901$ Belo Horizonte, MG, Brazil \\ ${ }^{\mathrm{c}}$ Department of Inorganic Chemistry, Fluminense Federal University, Outeiro de São João Batista, s/n, Centro, CEP 24020-141 Niterói, RJ, Brazil \\ ${ }^{\mathrm{d}}$ São Carlos Physics Institute - USP, Cx. Postal 369, CEP 13560-970 São Carlos, SP, Brazil \\ e Chemistry Institute, Federal University of Alfenas, Rua Gabriel Monteiro da Silva, 700, CEP 37130-000, Alfenas, MG, Brazil
}

\section{H I G H L I G H T S}

- Compound 3 crystallizes in the unusual space group $\mathrm{R} \overline{\mathrm{m}} \mathrm{m}$.

- Most ozonides crystallize in the monoclinic system with $\mathrm{P} 2{ }_{1} / \mathrm{c}$ space group as racemic crystal.

- Compound 3 space group represents only $\sim 0.04 \%$ of small-molecule crystal structures.

- X-ray crystallographic studies of stable polycyclic ozonides were carried out.

\section{A R T I C L E I N F O}

\section{Article history:}

Received 17 September 2014

Received in revised form 30 October 2014

Accepted 30 October 2014

Available online 8 November 2014

\section{Keywords:}

8-Oxabicycle[3.2.1]oct-6-en-3-one

Ozonides

Herbicides

Single crystal X-ray structure

\section{G R A P H I C A L A B S T R A C T}

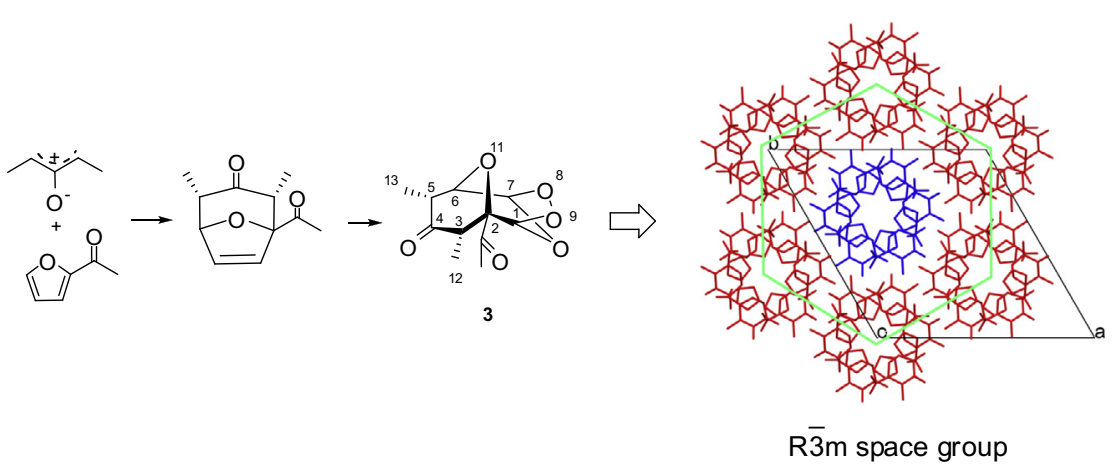

\section{A B S T R A C T}

The single crystal structure of seven tri- and tetracyclic ozonides derived from 8-oxabicycle[3.2.1]oct-6en-3-ones have been characterized by X-ray diffraction method. Five ozonides $(\mathbf{4}, \mathbf{5}, \mathbf{6}, \mathbf{7}$ and $\mathbf{8})$ crystallize in the monoclinic crystal system with $\mathrm{P} 2_{1} / \mathrm{c}$ space group. Compound $\mathbf{3}$ crystallize in the unusual centrosymmetric space group $\mathrm{R} \overline{3} \mathrm{~m}$, which represents $\sim 0.04 \%$ of the total number of structures know. The supramolecular structure of $\mathbf{3}$ forms infinite channels in a hexagram fashion, resulting in a honeycomb-like structure. Semi-empirical (PM6) and density functional theory methods (DFT) with the B3LYP functional and the 6-31G(d) basis set were used to optimize the geometries and compute structural parameters (bond lengths, angles and dihedral angles) that could be compared to the refined crystal structure. The theoretical results show good agreements with the experimental structure.

(c) 2014 Elsevier B.V. All rights reserved.

\section{Introduction}

Chemical crop protection plays a vital role in ensuring sufficient food supply to a growing world population, since the expansion of cultivated areas is not enough to allow a harvest increase at the

\footnotetext{
* Corresponding author at: Department of Chemistry, Federal University of Viçosa, Av. P.H. Rolfs, CEP 36570-000 Viçosa, MG, Brazil.

E-mail address: lcab@ufmg.br (L.C.A. Barbosa).
}

required rate $[1,2]$. To improve the world agriculture performance it is necessary to ensure an intensive control of pests, diseases, and specially selected weeds, always taking into account environmental issues. In the face of ever more stringent demands, the discovery of new agrochemicals has become an important research area since it contributes to reduce the losses in the production and storage of crops, reducing the costs of agricultural products [3-5].

Natural products can be used as models to inspire the synthesis of new bioactive molecules. In this context, artemisinin (1, Fig. 1), a 
(1)

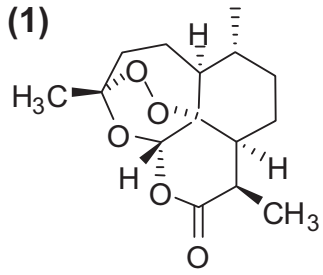

(2)

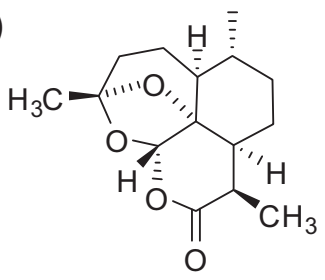

Fig. 1. Structures of artemisinin (1) and deoxyartemisinin (2).

secondary metabolite isolated from the shoots of sweet wormwood (Artemisia annua L.), and its semi synthetic analogs have a powerful inhibitory effect on plant growth [6-9]. Artemisinin and selected derivatives are also known for their antimalarial activity against multidrug-resistant forms of the parasite Plasmodium falciparum. In fact such compounds are widely used as antimalarial drugs as part of the Artemisinin Combination Therapy (ACT) protocols recommended by WHO [10].

The phytotoxic and antimalarial activities of these compounds are dependent upon the presence of the peroxide moiety, since deoxyartemisinin (2, Fig. 1) is inactive.

Following our ongoing research to develop new compounds with herbicidal and/or plant growth regulating activity [11-14], we have described the synthesis and biological activities of some stable ozonides $[15,16]$. This research was based on a seminal discovery by our group that several ozonides derived from oxabicyclic compounds are stable and endowed with activity against $P$. falciparum $[17,18]$. Several of such ozonides showed an appreciable stability that allowed their purification and characterization, although that class of compounds has been described as very unstable and explosive $[19,20]$.

Considering that there are few reports in the literature on X-ray studies of ozonides due to their general instability [21,22], and also taking into account the importance of molecular structure in the biological activities, in this work the crystal structures of a series of stable tri- and tetracyclic ozonides were investigated. The structural experimental results were analyzed and compared with computational studies in order to complete the compounds characterization.

\section{Experimental}

The ozonides (3-9) were prepared following the procedure previously described. All experimental detail and spectroscopic data are in accordance to the literature $[15,16]$.

\section{Single crystal X-ray diffraction studies}

Crystals of compounds 3-9 (Scheme 1) were obtained by warming each compound in hexane, followed by addition of some drops of dichloromethane until the solid was completely dissolved and the resulting solutions were left static at room temperature. White well-shaped single crystals suitably for X-ray analyses were formed after $24 \mathrm{~h}$. They were separated, washed with cold hexane, and dried. Single crystals of 3-9 were selected for the X-ray experiments. All measurements were made at room temperature (293 K) on an Enraf-Nonius Kappa-CCD diffractometer with graphite monochromated Mo K $\alpha$. The final unit cell parameters were based on all reflections. Data collection was made using the COLLECT software [23]; integration and scaling of the reflections were performed with the HKL Denzo-Scalepack software system [24]. The structures were solved and the models refined using the SHELXL2013 software [25]. Non-hydrogen atoms of all structures were clearly solved and full-matrix least-squares refinements of these atoms in $F^{2}$, with anisotropic thermal parameters, were carried out. Hydrogen atoms were positioned stereochemically and were refined with fixed individual displacement parameters [Uiso $(\mathrm{H})=1.5 \mathrm{Ueq}(\mathrm{C})$ for methyl groups or $1.2 \mathrm{Ueq}(\mathrm{C})$ methyne and methylene groups], using the SHELXL riding model with $\mathrm{C}-\mathrm{H}$ bond lengths of $0.96,1.00$ and $0.99 \AA$ for methyl, methyne and methylene groups, respectively. The hydroxyl $\mathrm{H}$ atom in $\mathbf{6}$ was located by difference Fourier synthesis and was refined with free coordinates and $\operatorname{Uiso}(H)=1.5 \mathrm{Ueq}(\mathrm{O})$. WINGX software [26] was

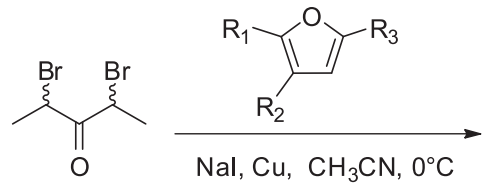

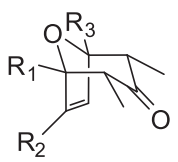

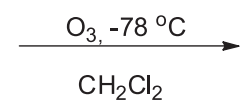<smiles>O=C1[C@H](Br)CCCC[C@H]1Br</smiles>

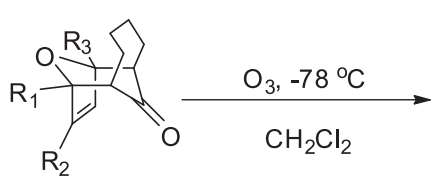

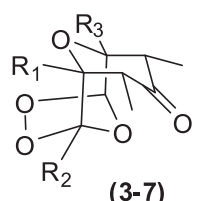

(3-7)

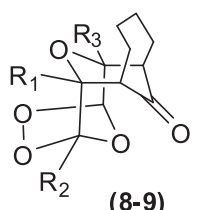

\begin{tabular}{lllll}
\hline \multirow{2}{*}{$\begin{array}{c}\text { Compound } \\
(\%)\end{array}$} & \multicolumn{3}{c}{ Substituents } \\
\cline { 3 - 5 } & \multicolumn{1}{c}{$\mathrm{R}_{1}$} & \multicolumn{1}{c}{$\mathrm{R}_{2}$} & $\mathrm{R}_{3}$ \\
\hline $\mathbf{3}$ & 98 & $\mathrm{COCH}_{3}$ & $\mathrm{H}$ & $\mathrm{H}$ \\
$\mathbf{4}$ & 100 & $\mathrm{CH}_{2} \mathrm{CH}_{3}$ & $\mathrm{H}$ & $\mathrm{H}$ \\
$\mathbf{5}$ & 50 & $\mathrm{CH}_{3}$ & $(\mathrm{CO}) \mathrm{OCH}_{3}$ & $\mathrm{H}$ \\
$\mathbf{6}$ & 75 & $\mathrm{CH}_{3}$ & $\mathrm{CH}_{2} \mathrm{OH}$ & $\mathrm{H}$ \\
7 & 100 & $\mathrm{CH}_{3}$ & $\mathrm{CH}_{2} \mathrm{OCH}$ & $\mathrm{H}$ \\
$\mathbf{8}$ & 42 & $\mathrm{CH}_{2} \mathrm{CH}_{3}$ & $\mathrm{H}$ & $\mathrm{H}$ \\
$\mathbf{9}$ & 55 & $\mathrm{CH}_{3}$ & $\mathrm{H}$ & $\mathrm{CH}_{3}$ \\
\hline
\end{tabular}

Scheme 1. Structures of ozonides 3-9. The yields correspond to the ozonolysis step $([15,16])$. 
Table 1

Crystal data and the structures refinement for compounds 3-9.

\begin{tabular}{|c|c|c|c|c|c|c|c|}
\hline Identification code & 3 & 4 & 5 & 6 & 7 & 8 & 9 \\
\hline $\begin{array}{l}\text { Empirical formula } \\
\text { Formula weight }\end{array}$ & $\begin{array}{l}\mathrm{C}_{11} \mathrm{H}_{14} \mathrm{O}_{6} \\
726.66\end{array}$ & $\begin{array}{l}\mathrm{C}_{11} \mathrm{H}_{16} \mathrm{O}_{5} \\
228.24\end{array}$ & $\begin{array}{l}\mathrm{C}_{12} \mathrm{H}_{16} \mathrm{O}_{7} \\
272.25\end{array}$ & $\begin{array}{l}\mathrm{C}_{11} \mathrm{H}_{16} \mathrm{O}_{6} \\
244.24\end{array}$ & $\begin{array}{l}\mathrm{C}_{12} \mathrm{H}_{18} \mathrm{O}_{6} \\
258.26\end{array}$ & $\begin{array}{l}\mathrm{C}_{13} \mathrm{H}_{18} \mathrm{O}_{5} \\
254.27\end{array}$ & $\begin{array}{l}\mathrm{C}_{13} \mathrm{H}_{18} \mathrm{O}_{5} \\
254.27\end{array}$ \\
\hline Temperature (K) & $293(2)$ & $293(2)$ & $293(2)$ & $293(2)$ & $293(2)$ & $293(2)$ & $293(2)$ \\
\hline Wavelength $(\AA)$ & 0.71073 & 0.71073 & 0.71073 & 0.71073 & 0.71073 & 0.71073 & 0.71073 \\
\hline Crystal system & Trigonal & Monoclinic & Monoclinic & Monoclinic & Monoclinic & Monoclinic & Orthorhombic \\
\hline Space group & R̄̄ $: H$ & $\mathrm{P} 2_{1} / \mathrm{c}$ & $\mathrm{P} 2_{1} / \mathrm{c}$ & $\mathrm{P} 2_{1} / \mathrm{c}$ & $\mathrm{P} 2_{1} / \mathrm{c}$ & $\mathrm{P} 2{ }_{1} / \mathrm{c}$ & P $22_{1} 2_{1} 2_{1}$ \\
\hline \multirow{6}{*}{ Unit cell dimensions $\left(\AA,^{\circ}\right)$} & $a=20.9551(4)$ & $a=5.6815(1)$ & $a=6.7575(3)$ & $a=5.8303(2)$ & $a=14.325(4)$ & $a=13.9049(4)$ & $a=8.0412(3)$ \\
\hline & $b=20.9551(4)$ & $b=22.3266(8)$ & $b=25.973(1)$ & $b=13.8797(4)$ & $b=7.095(2)$ & $b=8.5122(3)$ & $b=10.5123(3)$ \\
\hline & $c=13.1662(2)$ & $c=9.1255(3)$ & $c=8.9210(2)$ & $c=14.1242(3)$ & $c=12.811(4)$ & $c=10.8393(3)$ & $c=14.3276(5)$ \\
\hline & $\alpha=90$ & $\alpha=90$ & $\alpha=90$ & $\alpha=90$ & $\alpha=90$ & $\alpha=90$ & $\alpha=90$ \\
\hline & $\beta=90$ & $\beta=106.939(2)$ & $\beta=126.252(2)$ & $\beta=98.642(2)$ & $\beta=105.26(2)$ & $\beta=110.98$ & $\beta=90$ \\
\hline & $\beta=120$ & $\beta=90$ & $\gamma=90$ & $\gamma=90$ & $\gamma=90$ & $\gamma=90$ & $\gamma=90$ \\
\hline Volume $\left(\AA^{3}\right)$ & $5006.9(2)$ & $1107.31(6)$ & $1262.67(9)$ & 1129.9 & 1255.99(6) & $1197.88(7)$ & $1211.13(7)$ \\
\hline$Z$ & 18 & 4 & 4 & 4 & 4 & 4 & 4 \\
\hline Calc. Density $\left(\mathrm{Mg} / \mathrm{m}^{3}\right)$ & 1.446 & 1.369 & 1.432 & 1.436 & 1.366 & 1.410 & 1.395 \\
\hline$\mu\left(\mathrm{mm}^{-1}\right)$ & 0.119 & 0.108 & 0.119 & 0.117 & 0.110 & 0.108 & 0.107 \\
\hline$F(000)$ & 2304 & 488 & 576 & 520 & 552 & 544 & 544 \\
\hline Crystal size $\left(\mathrm{mm}^{3}\right)$ & $0.16 \times 0.20 \times 0.20$ & $0.10 \times 0.21 \times 0.53$ & $0.22 \times 0.29 \times 0.40$ & $0.15 \times 0.17 \times 0.41$ & $0.17 \times 0.33 \times 0.60$ & $0.18 \times 0.30 \times 0.32$ & $0.17 \times 0.21 \times 0.38$ \\
\hline$\theta_{\max }\left({ }^{\circ}\right)$ & 26.615 & 26.780 & 26.098 & 27.425 & 26.228 & 26.596 & 27.481 \\
\hline Index ranges & $-26 \leqslant h \leqslant 26$ & $-6 \leqslant h \leqslant 6$ & $-8 \leqslant h \leqslant 8$ & $-7 \leqslant h \leqslant 7$ & $-17 \leqslant h \leqslant 17$ & $-17 \leqslant h \leqslant 17$ & $-10 \leqslant h \leqslant 10$ \\
\hline & $-22 \leqslant k \leqslant 22$ & $-28 \leqslant k \leqslant 27$ & $-32 \leqslant k \leqslant 31$ & $-17 \leqslant k \leqslant 17$ & $-8 \leqslant k \leqslant 8$ & $-10 \leqslant k \leqslant 10$ & $-13 \leqslant k \leqslant 13$ \\
\hline & $-16 \leqslant l \leqslant 16$ & $-11 \leqslant l \leqslant 11$ & $-10 \leqslant l \leqslant 10$ & $-17 \leqslant l \leqslant 17$ & $-15 \leqslant l \leqslant 15$ & $-13 \leqslant l \leqslant 13$ & $-17 \leqslant l \leqslant 18$ \\
\hline Reflections collected & 4559 & 4006 & 4469 & 4276 & 4429 & 4341 & 5644 \\
\hline Independent reflections & $2297[R(\mathrm{int})=0.0226]$ & $2134[R($ int $)=0.0363]$ & $2375[R(\mathrm{int})=0.0385]$ & $2212[R($ int $)=0.0263]$ & $2489[R(\mathrm{int})=0.0267]$ & $2495[R(\mathrm{int})=0.0172]$ & $2662[R($ int $)=0.043]$ \\
\hline Completeness to $\theta_{\max }(\%)$ & 98.1 & 97.6 & 95.6 & 98.8 & 98.7 & 99.4 & 95.5 \\
\hline Data/restraints/parameters & $2297 / 0 / 157$ & $2134 / 0 / 148$ & $2375 / 0 / 176$ & $2212 / 0 / 158$ & 2489/0/167 & 2495/0/164 & $2662 / 0 / 165$ \\
\hline Goodness-of-fit on $F^{2}$ & 1.063 & 1.049 & 1.021 & 1.062 & 1.057 & 1.058 & 1.041 \\
\hline Final $R$ indices $[I>2 \sigma(I)]$ & $\begin{array}{l}R 1=0.0444, \\
\mathrm{w} R 2=0.1188\end{array}$ & $\begin{array}{l}R 1=0.0490, \\
\mathrm{w} R 2=0.1232\end{array}$ & $\begin{array}{l}R 1=0.0531, \\
\mathrm{w} R 2=0.1385\end{array}$ & $\begin{array}{l}R 1=0.0411, \\
w R 2=0.1085\end{array}$ & $\begin{array}{l}R 1=0.0497 \\
w R 2=0.1365\end{array}$ & $\begin{array}{l}R 1=0.0438 \\
\mathrm{w} R 2=0.1192\end{array}$ & $R 1=0.0385, \mathrm{w} R 2=0.0952$ \\
\hline$R$ indices (all data) & $\begin{array}{l}R 1=0.0597, \\
\mathrm{w} R 2=0.1293\end{array}$ & $\begin{array}{l}R 1=0.0759, \\
\mathrm{w} R 2=0.1370\end{array}$ & $\begin{array}{l}R 1=0.0814 \\
\mathrm{w} R 2=0.1578\end{array}$ & $\begin{array}{l}R 1=0.0567 \\
\mathrm{w} R 2=0.1185\end{array}$ & $\begin{array}{l}R 1=0.0621 \\
\mathrm{w} R 2=0.1471\end{array}$ & $\begin{array}{l}R 1=0.0539 \\
w R 2=0.1271\end{array}$ & $R 1=0.0478, \mathrm{w} R 2=0.1016$ \\
\hline Largest diff. peak and hole $\left(\mathrm{e}^{-3}\right)$ & 0.157 and -0.154 & 0.163 and -0.149 & 0.145 and -0.117 & 0.185 and -0.181 & 0.172 and -0.202 & 0.409 and -0.199 & 0.108 and -0.096 \\
\hline
\end{tabular}

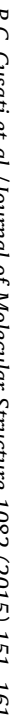

$\mu=$ absorption coefficient. 
used to analyze and prepare the data for publication. Molecular graphics were prepared using ORTEP-3 for Windows [27] and Mercury [28]. Crystal data, data collection procedures, structure determination methods and refinement results are summarized in Table 1.

\section{Computational details}

To identify the most stable conformation of each ozonide we employed the conformer distribution subroutine of the SPARTAN06 software [29] using the PM6 semi-empirical method [30] for geometry optimization. After location of the most stable conformation for each ozonide that conformation was re-optimized with the B3LYP functional [30] and the $6-31 \mathrm{G}(\mathrm{d})$ basis set [31]. The calculations of the coupling constant $(J)$ was performed for the optimized geometries using the B3LYP functional and the $6-311++G(2 d, p)$ basis set. The DFT calculations were carried out with the Gaussian09 software [32].

\section{Results and discussion}

Synthesis

All the ozonides have been previously prepared and their biological activities reported $[15,16]$ but no structural details were
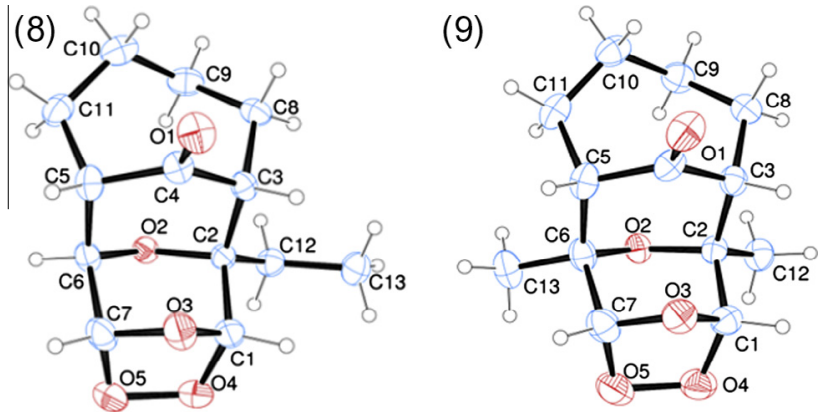

Fig. 3. ORTEP-3 views of the ozonides 8 and $\mathbf{9}$ showing the atom labeling of the tetracyclic structures and $30 \%$ probability ellipsoids. $\mathrm{H}$ atoms are shown as small spheres of arbitrary radii.

described. For clarity, we make a short description of their synthesis. For the preparation of the ozonides 3-7 the alkene cycloadducts precursors were prepared via a [4+3] cycloaddition between furans with the oxyallyl cation, generated in situ from 2,4-dibromopentan-3-one using standard literature procedure [15]. The alkenes were then submitted to ozonolysis to afford the 8,9,10,11-tetraoxatricyclo[5.2.1.12,6]oct-6-en-3-ones (ozonides 3-7, Scheme 1). The same cycloaddition procedure using the oxyallyl cation generated from 2,7-dibromocycloheptanone
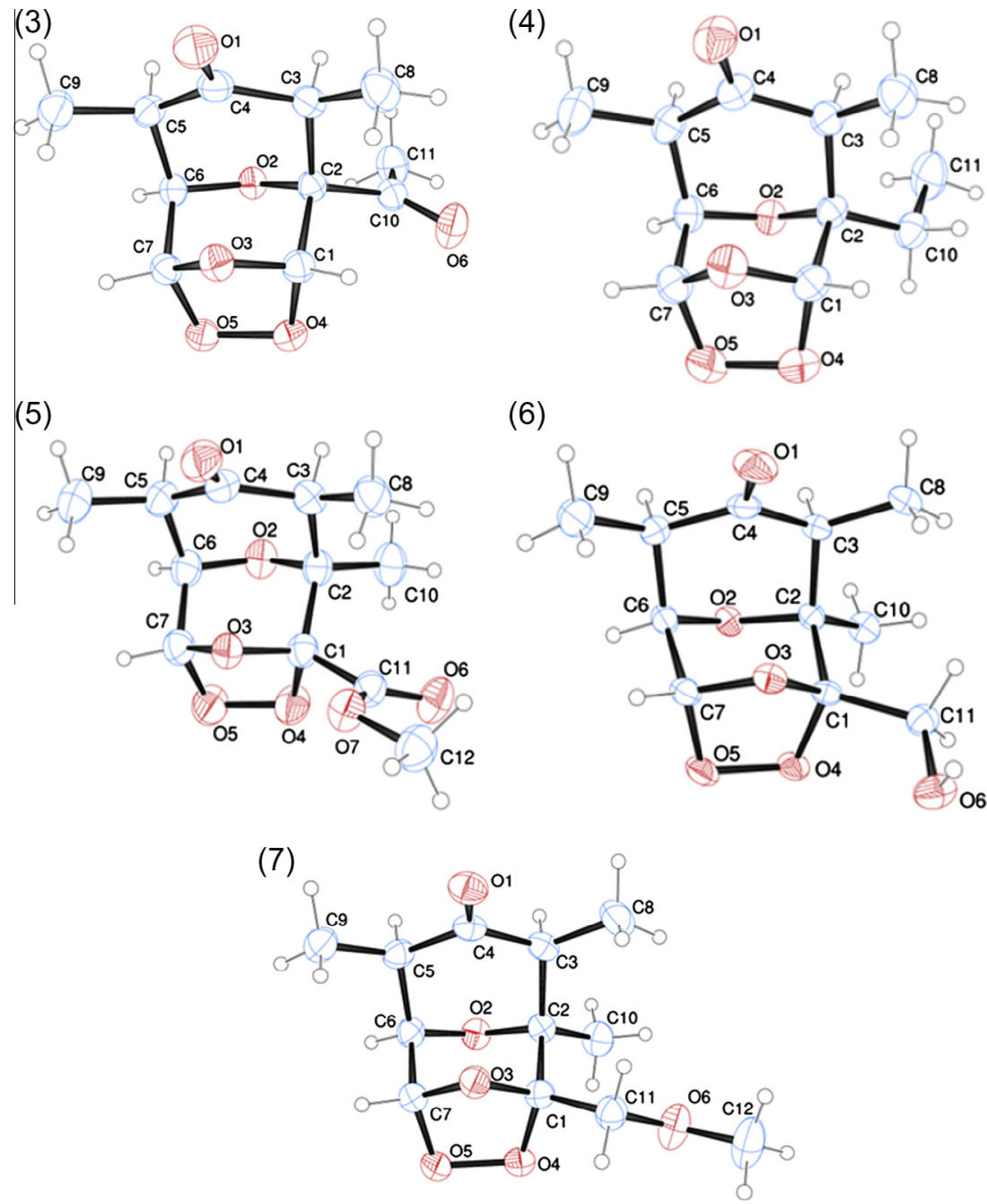

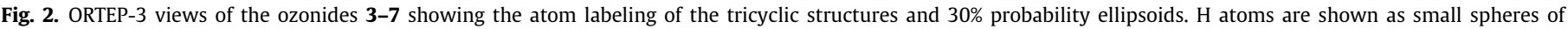
arbitrary radii. 
(a)

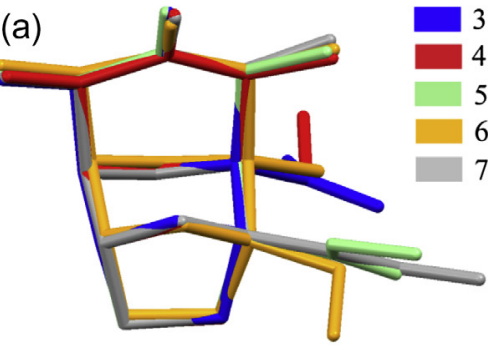

(b)

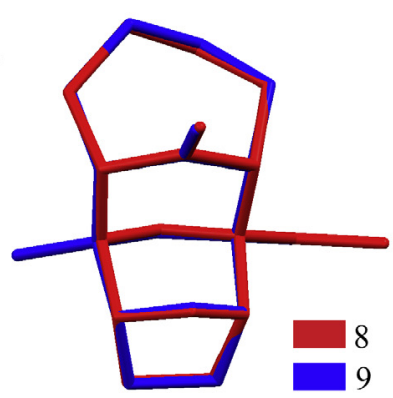

(c)

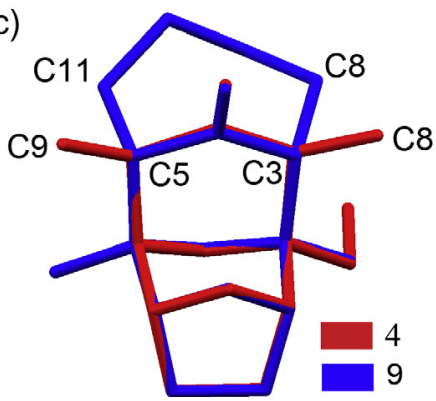

Fig. 4. Mercury views showing the superposition of equivalent enantiomers of (a) 3-7, (b) 8 and 9, (c) 4 and 9. The ozonides are labeled by color scheme. The hydrogen atoms were hidden for the representation clarity. (For interpretation of the references to color in this figure legend, the reader is referred to the web version of this article.)

with furans, afforded, upon ozonolysis, the 12-oxatricyclo[4.4.1.12,5] dodec-3-en-11-one adducts 8 and 9 (Scheme 1) [15,16].

As previously discussed, the yields of ozonolysis varied from $42 \%$ to $100 \%$ and no correlations between structure and yields were observed. Even though the spectroscopic data reported $[15,16]$ are consistent with the proposed structures, a full crystal analysis was carried out in order to shed light upon the influence of the substituents on the tridimensional form and crystal arrangement in the solid state.

\section{Crystal structure analysis}

The ORTEP-3 views of the tricyclic ozonides 3-7 are shown in Fig. 2. All compounds are chiral and crystallize in centrosymmetric space groups (Table 1). Therefore, their crystal structures are a 50:50 equimolar mixture of a pair of enantiomers in a well-defined arrangement. The enantiomers (C1(S), C2(S), C3(S), C5(R), C6(R), C7(R)) showed for 3, 4, 6, 7 and (C1(R), C2(S), C3(S), C5(R), C6(R), $C 7(R)$ ) showed for $\mathbf{5}$ in Fig. 2 were arbitrarily choose as asymmetric units for the tricyclic ozonides.

The ORTEP-3 views of the tetracyclic ozonides $\mathbf{8}$ and $\mathbf{9}$ are illustrated in Fig. 3. As observed for compounds 3-7, the ozonide $\mathbf{8}$ crystallizes in a centrosymmetric space group and therefore is a racemic crystal. The ozonide $\mathbf{9}$ was solved in the space group $\mathrm{P} 22_{1} 2_{1} 2_{1}$ and since it is a chiral molecule crystallized in a chiral space group containing just one molecule in the asymmetric unit, its crystal structure contains a pure enantiomer. However, it was not possible to determine the absolute structure of $\mathbf{9}$ using X-ray diffraction since it contains only electron-poor atoms, which does not have anomalous scattering large enough (using Mo K $\alpha$ radiation) to permit a reliably refined Flack parameter value [33]. The enantiomers showed in Fig. 3, (C1(R), C2(R), C3(S), C5(R), C6(S), C7(S)) and (C1(S), C2(S), C3(R), C5(S), C6(R), C7(R)) for 8 and 9 , respectively, were arbitrarily choose as asymmetric units for the tetracyclic ozonides.

Equivalent enantiomers of tricyclic ozonides 3-7 are superimposed in a capped stick fashion (Fig. 4a). The overlay of molecular backbones shows the conformational similarity between homologous atoms in the three fused rings and their first neighbor atoms. In other words, except for the moieties of the functional groups linked to $\mathrm{C} 1$ and $\mathrm{C} 2$, the remaining molecular geometry is very similar (see also Tables 4 and 5). The same features are observed when the tetracyclic ozonides $\mathbf{8}$ and $\mathbf{9}$ are compared (Fig. 4b). The overlay of molecular backbones of $\mathbf{4}$ (tricyclic) and $\mathbf{9}$ (tetracyclic) shows that the homologous three-fused rings are also geometrically identical (Fig. 4c). An important difference is only observed for the orientation of one of the three non-hydrogen atoms linked at $\mathrm{C} 3$ and $\mathrm{C} 5$ atoms, which points to front in the tricyclic ozonides (C8 and C9) and to the back in the tetracyclic ones (C8 and C11).

Taking into account the intermolecular interactions, dimmers assembled with inversion symmetry related molecules through intermolecular non-classical $\mathrm{H}$ bonds are common building blocks for the packing of the centrosymmetric ozonides 3-8 (Fig. 5). The hydrogen-bond motifs of the supramolecular dimmers are $\mathrm{R}_{2}^{2}(8)$ for 3, 4, and 6; $R_{2}^{2}(10)$ for 5 and 7; $R_{2}^{2}(12)$ for 8 [34]. The linkage via methyne strongest non-classical $\mathrm{H}$ bond donor [35] occurs to 3, 4, 6, and 8. In three of the five tricyclic ozonides, 3, 4 and 7, the $\mathrm{O} 1$ atom works as $\mathrm{H}$ bond acceptor forming the supramolecular synthons in which the inversion symmetry related molecules

Table 2

Comparison between the oxygen-oxygen bond lengths $(\AA)$ obtained by theoretical calculations and X-ray analysis.

\begin{tabular}{|c|c|c|c|}
\hline \multirow[t]{3}{*}{ Compound } & \multicolumn{3}{|c|}{ Oxygen $(4)^{\mathrm{a}}$-oxygen $(5)$ bond length $(\AA)$} \\
\hline & \multicolumn{2}{|l|}{ Theoretical calculations } & \multirow[t]{2}{*}{ X-ray data } \\
\hline & Semi-empirical (PM6) (error \%) ${ }^{\mathrm{b}}$ & DFT (B3LYP/6-31G(d)) (error \%) & \\
\hline 3 & $1.448(2.5)$ & $1.481(0.4)$ & $1.487(2)$ \\
\hline 4 & $1.447(3.0)$ & $1.481(0.7)$ & $1.492(2)$ \\
\hline 5 & $1.444(2.8)$ & $1.477(0.6)$ & $1.485(2)$ \\
\hline 6 & $1.442(3.8)$ & $1.472(1.8)$ & $1.499(2)$ \\
\hline 7 & $1.445(3.6)$ & $1.479(0.9)$ & $1.492(2)$ \\
\hline 8 & $1.449(3.1)$ & $1.482(0.9)$ & $1.495(3)$ \\
\hline 9 & $1.449(2.3)$ & $1.482(0.1)$ & $1.484(3)$ \\
\hline
\end{tabular}

a The numbers 4 and 5 in the oxygen refer only to the ORTEP representations.

b Values in brackets refer to the percentage error between experimental and theoretical computations. 
Table 3

X-ray and calculated bond lengths ( $(\AA)$ for ozonides 3-9.

\begin{tabular}{|c|c|c|c|c|c|c|c|c|c|c|c|c|c|c|c|}
\hline \multirow[t]{2}{*}{ Fragment } & \multicolumn{2}{|l|}{3} & \multicolumn{2}{|l|}{4} & \multicolumn{2}{|l|}{5} & \multicolumn{2}{|l|}{6} & \multicolumn{2}{|l|}{7} & \multirow[t]{2}{*}{ Fragment } & \multicolumn{2}{|c|}{8} & \multicolumn{2}{|l|}{9} \\
\hline & Bond length & DFT $^{*}$ & Bond length & DFT $^{*}$ & Bond length & $\mathrm{DFT}^{*}$ & Bond length & DFT $^{*}$ & Bond length & DFT $^{*}$ & & Bond length & DFT & Bond length & $\mathrm{DFT}^{*}$ \\
\hline$C(1)-C(2)$ & $1.532(2)$ & 1.548 & $1.528(2)$ & 1.551 & $1.556(3)$ & 1.552 & $1.614(2)$ & 1.564 & $1.563(2)$ & 1.568 & $C(1)-C(2)$ & $1.542(2)$ & 1.553 & $1.537(3)$ & 1.551 \\
\hline$C(1)-O(3)$ & $1.411(2)$ & 1.415 & $1.415(2)$ & 1.418 & $1.413(2)$ & 1.409 & $1.395(2)$ & 1.421 & $1.422(2)$ & 1.424 & $\mathrm{C}(1)-\mathrm{O}(3)$ & $1.418(2)$ & 1.416 & $1.421(3)$ & 1.415 \\
\hline$C(1)-O(4)$ & $1.421(2)$ & 1.425 & $1.432(2)$ & 1.426 & $1.444(2)$ & 1.444 & $1.381(2)$ & 1.450 & $1.439(2)$ & 1.441 & $\mathrm{C}(1)-\mathrm{O}(4)$ & $1.428(2)$ & 1.427 & $1.417(3)$ & 1.426 \\
\hline$C(2)-C(10)$ & $1.530(2)$ & 1.540 & $1.504(2)$ & 1.536 & $1.515(3)$ & 1.514 & $1.490(2)$ & 1.526 & $1.508(2)$ & 1.525 & $C(10)-C(11)$ & $1.535(3)$ & 1.542 & $1.523(4)$ & 1.542 \\
\hline$C(2)-C(3)$ & $1.550(2)$ & 1.563 & $1.543(2)$ & 1.558 & $1.546(3)$ & 1.584 & $1.502(2)$ & 1.566 & $1.550(2)$ & 1.565 & $C(2)-C(12)$ & $1.524(2)$ & 1.535 & $1.508(3)$ & 1.524 \\
\hline $\mathrm{C}(2)-\mathrm{O}(2)$ & $1.429(2)$ & 1.431 & $1.443(2)$ & 1.439 & $1.433(2)$ & 1.429 & $1.466(2)$ & 1.444 & $1.445(2)$ & 1.446 & $C(2)-C(3)$ & $1.541(2)$ & 1.560 & $1.543(3)$ & 1.557 \\
\hline$C(3)-C(4)$ & $1.528(2)$ & 1.544 & $1.512(2)$ & 1.539 & $1.515(3)$ & 1.538 & $1.509(2)$ & 1.538 & $1.518(2)$ & 1.538 & $\mathrm{C}(2)-\mathrm{O}(2)$ & $1.435(2)$ & 1.442 & $1.444(2)$ & 1.439 \\
\hline$C(3)-C(8)$ & $1.522(2)$ & 1.532 & $1.524(2)$ & 1.533 & $1.529(3)$ & 1.531 & $1.517(2)$ & 1.533 & $1.524(3)$ & 1.534 & $C(3)-C(4)$ & $1.523(2)$ & 1.528 & $1.513(3)$ & 1.528 \\
\hline$C(4)-C(5)$ & $1.521(2)$ & 1.535 & $1.526(2)$ & 1.536 & $1.514(3)$ & 1.537 & $1.512(3)$ & 1.534 & $1.516(2)$ & 1.535 & $C(3)-C(8)$ & $1.544(2)$ & 1.565 & $1.542(3)$ & 1.563 \\
\hline $\mathrm{C}(4)-\mathrm{O}(1)$ & $1.212(2)$ & 1.213 & $1.210(2)$ & 1.215 & $1.218(2)$ & 1.215 & $1.157(2)$ & 1.215 & $1.210(2)$ & 1.216 & $C(4)-C(5)$ & $1.516(2)$ & 1.528 & $1.513(3)$ & 1.528 \\
\hline$C(5)-C(6)$ & $1.527(2)$ & 1.541 & $1.521(3)$ & 1.543 & $1.528(3)$ & 1.545 & $1.475(2)$ & 1.544 & $1.527(2)$ & 1.544 & $\mathrm{C}(4)-\mathrm{O}(1)$ & $1.214(2)$ & 1.215 & $1.225(2)$ & 1.216 \\
\hline$C(5)-C(9)$ & $1.522(2)$ & 1.531 & $1.516(3)$ & 1.531 & $1.518(3)$ & 1.531 & $1.512(3)$ & 1.530 & $1.518(2)$ & 1.530 & $C(5)-C(11)$ & $1.558(2)$ & 1.562 & $1.566(3)$ & 1.563 \\
\hline$C(6)-C(7)$ & $1.516(2)$ & 1.539 & $1.519(2)$ & 1.539 & $1.510(3)$ & 1.539 & $1.585(2)$ & 1.535 & $1.522(2)$ & 1.534 & $C(5)-C(6)$ & $1.527(2)$ & 1.546 & $1.540(3)$ & 1.557 \\
\hline $\mathrm{C}(6)-\mathrm{O}(2)$ & $1.432(2)$ & 1.430 & $1.431(2)$ & 1.426 & $1.425(2)$ & 1.428 & $1.424(2)$ & 1.424 & $1.420(2)$ & 1.423 & $C(6)-C(7)$ & $1.515(2)$ & 1.539 & $1.538(3)$ & 1.551 \\
\hline $\mathrm{C}(7)-\mathrm{O}(3)$ & $1.417(2)$ & 1.419 & $1.422(2)$ & 1418 & $1.418(2)$ & 1.420 & $1.428(2)$ & 1.418 & $1.419(2)$ & 1.416 & $\mathrm{C}(6)-\mathrm{O}(2)$ & $1.437(2)$ & 1.430 & $1.437(2)$ & 1.439 \\
\hline$C(7)-O(5)$ & $1.425(2)$ & 1.423 & $1.424(2)$ & 1.424 & $1.417(3)$ & 1.420 & $1.382(2)$ & 1.419 & $1.424(2)$ & 1.419 & $C(7)-O(3)$ & $1.422(2)$ & 1.418 & $1.414(3)$ & 1.415 \\
\hline $\mathrm{O}(4)-\mathrm{O}(5)$ & $1.487(2)$ & 1.481 & $1.492(2)$ & 1.481 & $1.485(2)$ & 1.477 & $1.499(2)$ & 1.472 & $1.492(2)$ & 1.479 & $C(7)-O(5)$ & $1.420(3)$ & 1.424 & $1.423(3)$ & 1.426 \\
\hline$C(1)-C(11)$ & - & - & - & - & $1.524(3)$ & 1.535 & $1.572(2)$ & 1.537 & $1.510(2)$ & 1.542 & $C(8)-C(9)$ & $1.515(3)$ & 1.542 & $1.520(3)$ & 1.542 \\
\hline$C(10)-C(11)$ & $1.481(2)$ & 1.508 & $1.504(3)$ & 1.532 & - & - & - & - & - & - & $C(9)-C(10)$ & $1.514(3)$ & 1.569 & $1.526(4)$ & 1.568 \\
\hline$C(10)-O(6)$ & $1.206(2)$ & 1.217 & - & - & - & - & - & - & - & - & $\mathrm{O}(4)-\mathrm{O}(5)$ & $1.484(2)$ & 1.482 & $1.495(3)$ & 1.482 \\
\hline$C(11)-O(7)$ & - & - & - & - & $1.198(2)$ & 1.204 & - & - & - & - & $C(6)-C(13)$ & - & - & $1.521(3)$ & 1.524 \\
\hline$C(11)-O(6)$ & - & - & - & - & $1.314(2)$ & 1.343 & $1.451(2)$ & 1.436 & $1.390(2)$ & 1.406 & $C(12)-C(13)$ & $1.526(2)$ & 1.534 & - & - \\
\hline$C(12)-O(6)$ & - & - & - & - & - & - & - & - & $1.413(3)$ & 1.423 & & & & & \\
\hline $\mathrm{C}(12)-\mathrm{O}(7)$ & - & - & - & - & $1.452(2)$ & 1.442 & - & - & - & - & & & & & \\
\hline
\end{tabular}

B3LYP/6-31G(d) method. 
Table 4

X-ray and calculated bond angles () for ozonides 3-9.

\begin{tabular}{|c|c|c|c|c|c|c|c|c|c|c|c|c|c|c|c|}
\hline \multirow[t]{2}{*}{ Fragment } & \multicolumn{2}{|l|}{3} & \multicolumn{2}{|l|}{4} & \multicolumn{2}{|l|}{5} & \multicolumn{2}{|l|}{6} & \multicolumn{2}{|l|}{7} & \multirow[t]{2}{*}{ Fragment } & \multicolumn{2}{|l|}{8} & \multicolumn{2}{|l|}{9} \\
\hline & Bond angle & DFT $^{*}$ & Bond angle & DFT $^{*}$ & Bond angle & DFT $^{*}$ & Bond angle & $\mathrm{DFT}^{*}$ & Bond angle & $\mathrm{DFT}^{*}$ & & Bond angle & $\mathrm{DFT}^{*}$ & Bond angle & DFT $^{*}$ \\
\hline$C(1)-C(2)-C(10)$ & $108.99(12)$ & 109.00 & $110.32(14)$ & 109.62 & $113.34(16)$ & 112.35 & $110.50(13)$ & 112.29 & $113.23(14)$ & 112.70 & $C(1)-C(2)-C(12)$ & $110.18(13)$ & 110.47 & $110.86(17)$ & 109.77 \\
\hline$C(1)-C(2)-C(3)$ & $111.36(11)$ & 111.96 & $110.14(14)$ & 110.99 & $111.06(15)$ & 114.48 & $116.60(12)$ & 113.92 & $113.29(13)$ & 114.03 & $C(1)-C(2)-C(3)$ & $109.45(12)$ & 110.93 & $106.25(16)$ & 110.14 \\
\hline$C(1)-O(3)-C(7)$ & $99.90(10)$ & 99.54 & $99.68(13)$ & 99.38 & $100.67(14)$ & 99.99 & $104.15(11)$ & 100.78 & $101.50(12)$ & 100.98 & $C(1)-O(3)-C(7)$ & $98.83(13)$ & 99.60 & $99.06(16)$ & 99.62 \\
\hline $\mathrm{C}(1)-\mathrm{O}(4)-\mathrm{O}(5)$ & 103.71(10) & 103.99 & $103.54(12)$ & 103.95 & 103.91(12) & 104.15 & $105.31(10)$ & 105.29 & 104.86(11) & 105.28 & $\mathrm{C}(1)-\mathrm{O}(4)-\mathrm{O}(5)$ & 104.08(13) & 103.93 & 103.39(17) & 103.81 \\
\hline$C(2)-C(3)-C(4)$ & $109.50(11)$ & 110.61 & $112.17(15)$ & 111.59 & $112.14(15)$ & 110.80 & $110.49(13)$ & 111.77 & $111.23(13)$ & 111.46 & $C(2)-C(3)-C(4)$ & $112.35(11)$ & 110.18 & $111.39(16)$ & 109.86 \\
\hline$C(2)-C(3)-C(8)$ & $115.19(13)$ & 115.89 & $114.18(14)$ & 115.64 & $115.21(16)$ & 115.76 & $113.49(14)$ & 118.16 & $117.09(15)$ & 118.26 & $C(2)-C(3)-C(8)$ & $114.26(11)$ & 111.59 & $116.57(17)$ & 111.84 \\
\hline$C(2)-O(2)-C(6)$ & $110.46(10)$ & 111.64 & $111.35(12)$ & 112.19 & $112.03(14)$ & 111.02 & 113.61(11) & 112.93 & $112.43(11)$ & 113.16 & $C(2)-O(2)-C(6)$ & $110.74(10)$ & 111.86 & 111.69(14) & 112.78 \\
\hline$C(3)-C(2)-C(10)$ & $111.81(11)$ & 111.32 & $114.12(15)$ & 114.18 & $112.73(17)$ & 111.93 & $110.83(13)$ & 112.53 & $112.93(14)$ & 112.51 & $C(3)-C(2)-C(12)$ & $114.52(11)$ & 114.94 & 114.44(17) & 114.23 \\
\hline$C(3)-C(4)-C(5)$ & $117.18(13)$ & 117.59 & $116.50(15)$ & 116.88 & 117.04(17) & 116.61 & $118.22(14)$ & 116.59 & $115.17(14)$ & 116.56 & $C(3)-C(4)-C(5)$ & $117.26(12)$ & 114.22 & $117.60(16)$ & 114.20 \\
\hline$C(4)-C(3)-C(8)$ & $111.99(14)$ & 111.02 & $112.04(15)$ & 111.05 & 111.77(17) & 111.96 & $114.57(14)$ & 110.74 & $112.71(15)$ & 111.13 & $C(3)-C(8)-C(9)$ & $117.10(13)$ & 115.16 & $116.50(18)$ & 115.04 \\
\hline$C(4)-C(5)-C(6)$ & $110.60(12)$ & 110.24 & $110.13(14)$ & 109.97 & $109.44(15)$ & 110.48 & $104.32(13)$ & 109.68 & $109.84(13)$ & 109.85 & $C(4)-C(3)-C(8)$ & $107.37(12)$ & 107.84 & $107.97(17)$ & 108.91 \\
\hline$C(4)-C(5)-C(9)$ & $112.96(13)$ & 112.15 & $112.77(16)$ & 112.22 & $113.26(18)$ & 112.21 & $116.78(17)$ & 112.33 & $114.18(15)$ & 112.34 & $C(4)-C(5)-C(11)$ & $110.10(12)$ & 109.29 & 108.99(19) & 109.16 \\
\hline$C(5)-C(6)-C(7)$ & $112.03(12)$ & 113.44 & $112.05(14)$ & 112.84 & $112.57(17)$ & 113.12 & $115.04(14)$ & 112.67 & $112.03(14)$ & 113.00 & $C(4)-C(5)-C(6)$ & $110.22(13)$ & 109.12 & 110.61(18) & 109.86 \\
\hline$C(6)-C(5)-C(9)$ & $113.53(13)$ & 114.79 & $114.18(17)$ & 114.85 & $114.28(17)$ & 114.77 & $112.23(15)$ & 114.97 & $113.39(15)$ & 114.88 & $C(5)-C(11)-C(10)$ & $117.90(14)$ & 114.93 & $117.70(2)$ & 115.04 \\
\hline $\mathrm{C}(7)-\mathrm{O}(5)-\mathrm{O}(4)$ & $103.80(10)$ & 103.74 & $103.84(13)$ & 103.76 & 103.99(12) & 103.43 & $104.85(10)$ & 103.14 & $103.68(11)$ & 103.42 & $C(5)-C(6)-C(7)$ & 111.63(13) & 111.81 & 109.48(17) & 110.14 \\
\hline$O(1)-C(4)-C(3)$ & $121.16(15)$ & 120.96 & $122.06(17)$ & 121.55 & $121.30(18)$ & 121.68 & $121.02(17)$ & 121.70 & $122.36(16)$ & 121.75 & $C(6)-C(5)-C(11)$ & $111.53(12)$ & 110.53 & $113.55(17)$ & 111.84 \\
\hline$O(1)-C(4)-C(5)$ & $121.55(15)$ & 121.31 & $121.33(17)$ & 121.40 & $121.55(19)$ & 121.57 & $120.69(17)$ & 121.57 & $122.39(16)$ & 121.65 & $\mathrm{C}(7)-\mathrm{O}(5)-\mathrm{O}(4)$ & 103.23(12) & 103.77 & $103.55(16)$ & 103.81 \\
\hline $\mathrm{O}(2)-\mathrm{C}(2)-\mathrm{C}(1)$ & $108.93(11)$ & 108.04 & $106.78(13)$ & 107.09 & $106.06(14)$ & 107.14 & $108.37(12)$ & 106.09 & $105.84(12)$ & 106.23 & $C(8)-C(9)-C(10)$ & $114.84(14)$ & 116.50 & $114.83(18)$ & 116.47 \\
\hline$O(2)-C(2)-C(10)$ & $106.60(11)$ & 107.72 & $106.82(13)$ & 106.14 & $104.75(15)$ & 105.99 & $107.55(12)$ & 104.78 & 103.97(13) & 104.18 & $C(9)-C(10)-C(11)$ & $117.22(15)$ & 116.53 & $115.60(2)$ & 116.47 \\
\hline$O(2)-C(2)-C(3)$ & $109.00(11)$ & 108.64 & $108.33(12)$ & 108.14 & $108.36(15)$ & 108.83 & $102.30(12)$ & 106.37 & 106.62(13) & 106.23 & $O(1)-C(4)-C(3)$ & $120.38(13)$ & 122.64 & $120.60(2)$ & 122.63 \\
\hline$O(2)-C(6)-C(5)$ & $109.62(11)$ & 108.87 & $110.04(14)$ & 109.25 & $110.10(16)$ & 109.40 & $109.21(13)$ & 109.49 & $110.78(13)$ & 109.62 & $\mathrm{O}(1)-\mathrm{C}(4)-\mathrm{C}(5)$ & $122.09(14)$ & 122.65 & $121.45(19)$ & 122.63 \\
\hline $\mathrm{O}(2)-\mathrm{C}(6)-\mathrm{C}(7)$ & $108.67(11)$ & 108.43 & $108.93(13)$ & 108.58 & 108.93(16) & 108.56 & $106.89(12)$ & 108.77 & $108.29(13)$ & 108.23 & $O(2)-C(2)-C(1)$ & $107.28(11)$ & 106.59 & 108.09(17) & 107.08 \\
\hline$O(3)-C(1)-C(2)$ & $109.85(11)$ & 109.19 & $111.32(13)$ & 109.95 & 109.10(14) & 108.91 & $106.97(11)$ & 108.52 & 109.12(12) & 108.53 & $\mathrm{O}(2)-\mathrm{C}(2)-\mathrm{C}(12)$ & $105.90(11)$ & 105.52 & $106.03(16)$ & 106.71 \\
\hline $\mathrm{O}(3)-\mathrm{C}(1)-\mathrm{O}(4)$ & $104.07(11)$ & 104.62 & $103.70(14)$ & 104.24 & $104.10(14)$ & 104.88 & $101.33(12)$ & 103.96 & $103.65(12)$ & 103.69 & $O(2)-C(2)-C(3)$ & $109.22(11)$ & 107.88 & $111.07(15)$ & 108.60 \\
\hline$O(3)-C(7)-C(6)$ & $108.98(11)$ & 109.21 & $109.07(15)$ & 108.92 & $109.03(15)$ & 109.24 & $112.84(12)$ & 108.98 & $108.37(13)$ & 108.73 & $\mathrm{O}(2)-\mathrm{C}(6)-\mathrm{C}(5)$ & $110.37(11)$ & 109.83 & $108.84(16)$ & 108.60 \\
\hline $\mathrm{O}(3)-\mathrm{C}(7)-\mathrm{O}(5)$ & 104.11(11) & 104.63 & $103.72(14)$ & 104.57 & 103.31(15) & 104.07 & $98.17(12)$ & 104.15 & $103.82(13)$ & 104.56 & $O(2)-C(6)-C(7)$ & 109.07(13) & 108.07 & 107.98(18) & 107.08 \\
\hline$O(4)-C(1)-C(2)$ & $110.49(11)$ & 110.50 & $111.25(14)$ & 111.38 & 109.41(15) & 108.71 & 109.67(11) & 108.08 & $108.33(13)$ & 108.62 & $\mathrm{O}(3)-\mathrm{C}(1)-\mathrm{C}(2)$ & $110.34(13)$ & 110.48 & 109.79(17) & 110.04 \\
\hline$O(5)-C(7)-C(6)$ & $111.27(12)$ & 110.85 & $111.39(14)$ & 111.14 & $112.44(18)$ & 111.70 & $113.88(13)$ & 111.99 & $111.36(15)$ & 111.49 & $\mathrm{O}(3)-\mathrm{C}(1)-\mathrm{O}(4)$ & $104.29(13)$ & 104.02 & 104.04(19) & 104.11 \\
\hline$C(2)-C(1)-C(11)$ & - & - & - & - & $117.30(15)$ & 117.80 & 119.51(13) & 120.70 & 120.61(14) & 120.60 & $\mathrm{O}(3)-\mathrm{C}(7)-\mathrm{C}(6)$ & $109.42(12)$ & 108.70 & $110.88(18)$ & 110.04 \\
\hline$C(2)-C(10)-C(11)$ & $119.08(14)$ & 118.09 & $115.72(16)$ & 115.06 & - & - & - & - & - & - & $\mathrm{O}(3)-\mathrm{C}(7)-\mathrm{O}(5)$ & $104.36(15)$ & 104.39 & $104.00(2)$ & 104.11 \\
\hline$C(11)-O(6)-C(12)$ & - & - & - & - & - & - & - & - & 111.99(17) & 114.86 & $\mathrm{O}(4)-\mathrm{C}(1)-\mathrm{C}(2)$ & $110.60(13)$ & 110.98 & $112.51(17)$ & 111.28 \\
\hline$C(11)-O(7)-C(12)$ & & & & & $116.34(16)$ & 115.28 & - & - & - & - & $O(5)-C(7)-C(6)$ & 112.14(15) & 111.41 & 111.54(18) & 111.28 \\
\hline$O(3)-C(1)-C(11)$ & - & - & - & - & $111.23(15)$ & 109.98 & $114.27(12)$ & 108.96 & $105.48(13)$ & 105.93 & $C(5)-C(6)-C(13)$ & - & - & $114.70(2)$ & 114.23 \\
\hline $\mathrm{O}(4)-\mathrm{C}(1)-\mathrm{C}(11)$ & - & - & - & - & $104.80(14)$ & 105.74 & $103.47(12)$ & 105.33 & $108.37(13)$ & 108.18 & $C(7)-C(6)-C(13)$ & - & - & 108.63(19) & 109.77 \\
\hline $\mathrm{O}(6)-\mathrm{C}(11)-\mathrm{C}(1)$ & - & - & - & - & $112.52(16)$ & 109,22 & $115.40(14)$ & 112.30 & $110.80(15)$ & 116.10 & $O(2)-C(6)-C(13)$ & - & - & 106.96(17) & 108.60 \\
\hline $\mathrm{O}(6)-\mathrm{C}(10)-\mathrm{C}(11)$ & $121.83(15)$ & 123.04 & - & - & - & - & - & - & - & - & $C(2)-C(12)-C(13)$ & $114.55(14)$ & 115.68 & - & - \\
\hline $\mathrm{O}(6)-\mathrm{C}(10)-\mathrm{C}(2)$ & $119.09(14)$ & 118.86 & - & - & - & - & - & - & - & - & & & & & \\
\hline $\mathrm{O}(7)-\mathrm{C}(11)-\mathrm{C}(1)$ & - & - & - & - & $121.82(19)$ & 124.99 & - & - & - & - & & & & & \\
\hline $\mathrm{O}(7)-\mathrm{C}(11)-\mathrm{O}(6)$ & - & - & - & - & $125.66(19)$ & 125.77 & - & - & - & - & & & & & \\
\hline
\end{tabular}

B3LYP/6-31G(d) method. 
Table 5

Comparison between computed and experimental values for the H5-C5-C6-H6 dihedral angle and coupling constant $J_{5,6}$.

\begin{tabular}{|c|c|c|c|c|c|}
\hline \multirow[t]{3}{*}{ Compd. } & \multicolumn{3}{|l|}{ Dihedral angle ( $\phi$ H5-C5-C6-H6) } & \multicolumn{2}{|c|}{ Coupling constant $(\mathrm{J} / \mathrm{Hz}), \mathrm{H}-5$ and $\mathrm{H}-6$} \\
\hline & \multicolumn{2}{|l|}{ Theoretical calculations } & \multirow[t]{2}{*}{ X-ray data } & \multirow[t]{2}{*}{ Experimental } & \multirow[t]{2}{*}{ Theoretical (B3LYP/6-311++g(2d,p)) (error \%) } \\
\hline & Semi-empirical (PM6) (error \%) ${ }^{a}$ & DFT (B3LYP/6-31G(d)) (error \%)a & & & \\
\hline 3 & $-48.5^{\circ}(12.1)$ & $-55.2^{\circ}(0.0)$ & $-55.2^{\circ}$ & 6.9 & $6.8(1.4)$ \\
\hline 4 & $-49.1^{\circ}(13.2)$ & $-56.0^{\circ}(1.1)$ & $-56.6^{\circ}$ & 7.2 & $7.2(0.0)$ \\
\hline 5 & $-49.2^{\circ}(13.7)$ & $-55.5^{\circ}(2.6)$ & $-57.0^{\circ}$ & 6.5 & $6.6(1.5)$ \\
\hline 6 & $-50.1^{\circ}(16.1)$ & $-55.6^{\circ}(6.9)$ & $-59.7^{\circ}$ & 7.0 & $7.2(2.8)$ \\
\hline 7 & $-50.1^{\circ}(11.3)$ & $-54.8^{\circ}(3.0)$ & $-56.5^{\circ}$ & 6.8 & $6.7(1.5)$ \\
\hline 8 & $72.5^{\circ}(2.7)$ & $70.6^{\circ}(0.0)$ & $70.6^{\circ}$ & $-\mathrm{b}$ & - \\
\hline $\mathbf{9}^{\mathrm{c}}$ & - & - & - & - & - \\
\hline
\end{tabular}

a Values in brackets refer to the percentage (\%) error between experimental and theoretical measures.

b Do not measured due to the signal was a multiplet.

${ }^{\mathrm{c}}$ In the ozonide $\mathbf{9}$ there is a methyl group on the C6.

(a)
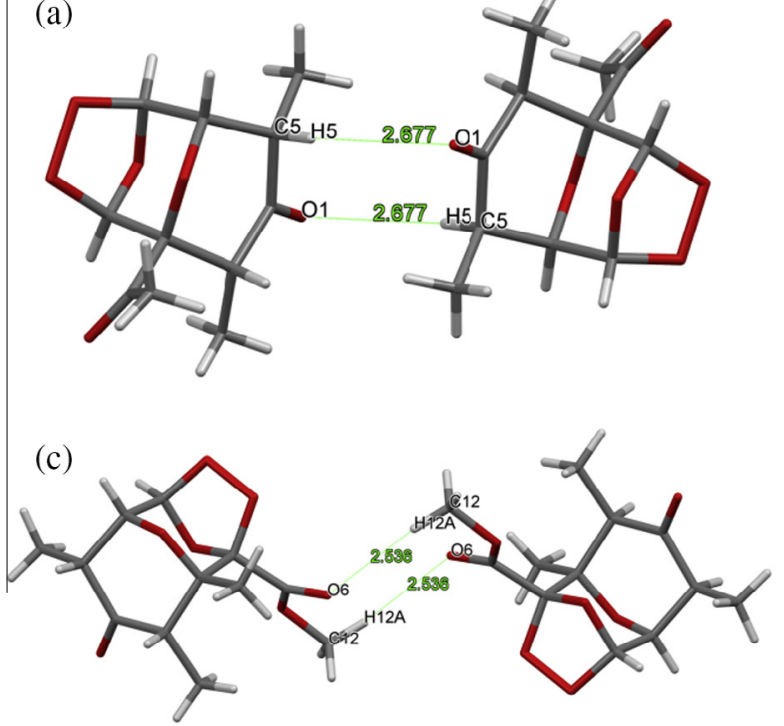

(e)

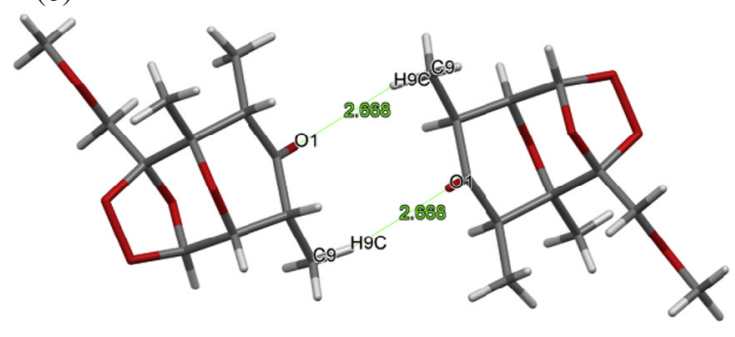

(b)

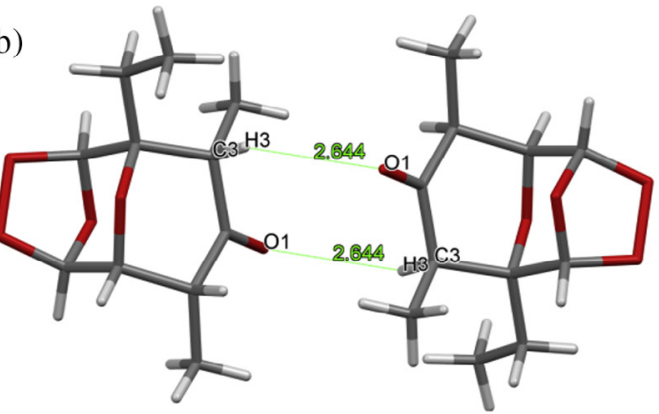

(d)
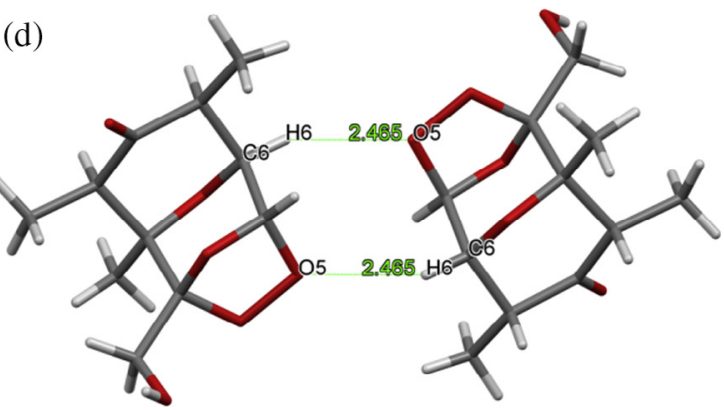

(f)

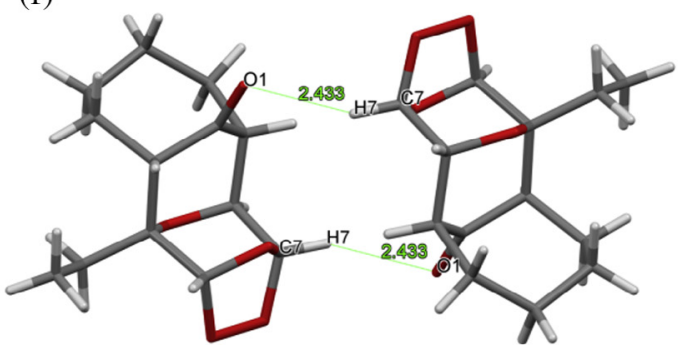

Fig. 5. Mercury views of the centrosymmetric dimmer formed for (a) 3; (b) 4; (c) 5; (d) 6; (e) 7; and (f) 8. The H bond distances (Å) are also shown.

present very similar orientation, especially for $\mathbf{3}$ and $\mathbf{4}$. 01 atom also appears as $\mathrm{H}$ bond acceptor for the tetracyclic ozonide $\mathbf{8}$.

The centrosymmetric dimmers are themselves linked by classical (ozonide 6, Fig. 6) and non-classical (e.g., for ozonide 4, Fig. 7) $\mathrm{H}$ bonds, and Van de Waals forces (for all ozonides). The whole dimmer staking is exemplified for ozonide 4 in Fig. 8. The remaining ones are showed in Supplementary Materials.

The packing of the non-centrosymmetric structure 9, where the molecules are related to $2_{1}$-screw axis is also governed by non-classical $\mathrm{H}$ bond. The strongest are those involving the $\mathrm{C}_{\mathrm{sp}}^{3}$-methynes $\mathrm{C} 1-\mathrm{H} 1$ and $\mathrm{C} 5-\mathrm{H} 5$, which act as donors to the bifurcated acceptor 01 . The linkage forms infinite double chains parallel to [100] (Fig. 9).

Due to the unusual supramolecular feature of compound 3 we are going to discuss its packing system in more detail. The centrosymmetric dimmers in $\mathbf{3}$ (Fig. 5a) are themselves centrosymmetric linked by other hydrogen-bond motifs of the type $R_{2}^{2}(8)$ forming infinite chains along [211] directions (Fig. 10). Another interesting 


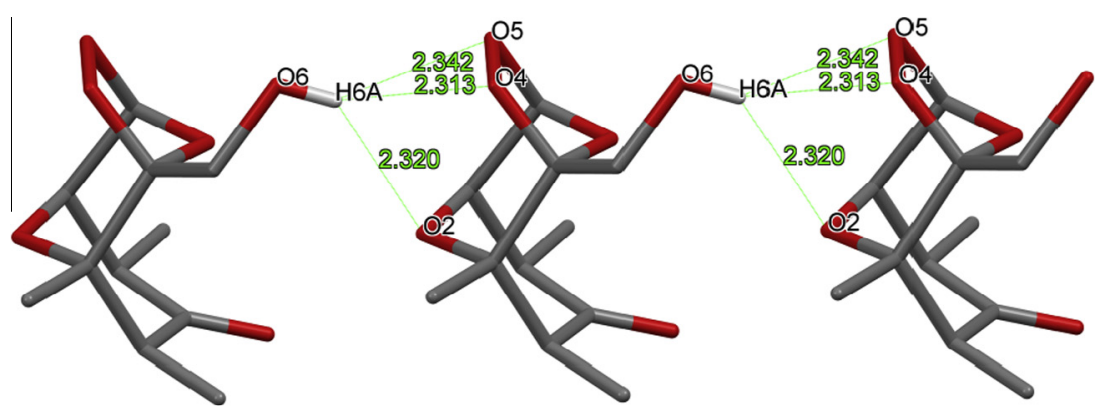

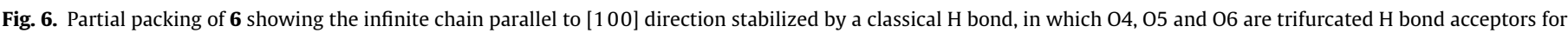
O-H6A donor. Some H. . acceptor separations $(\AA)$ are shown. Hydrogen atoms not involved in the H bonds were hidden for representation clarity.

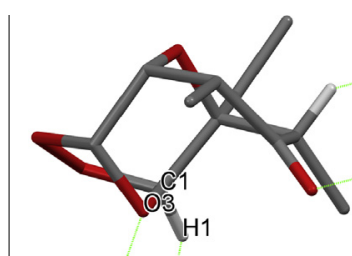

2.629
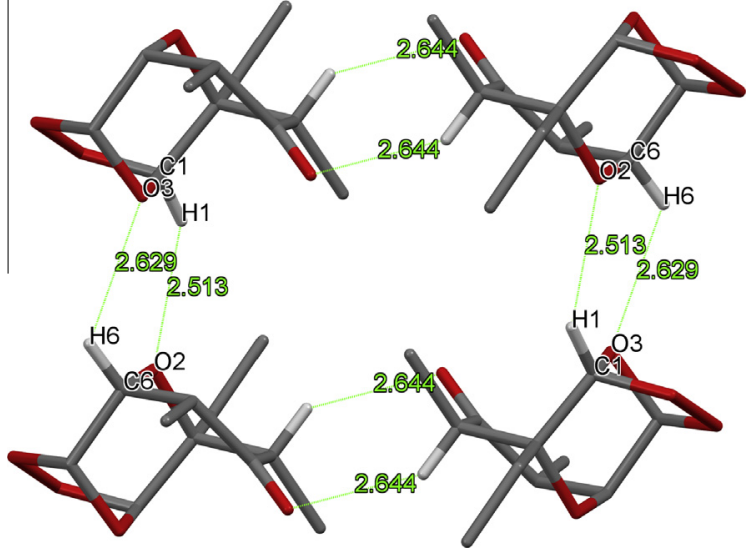

2.513

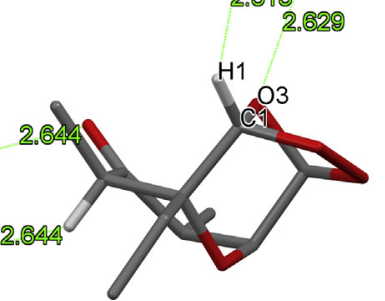

Fig. 7. Partial packing of $\mathbf{4}$ showing a supramolecular moiety stabilized by nonclassical $\mathrm{H}$ bonds. Some H. . acceptor separations $(\AA)$ are shown. Hydrogen atoms not involved in the $\mathrm{H}$ bonds were hidden for representation clarity.

supramolecular linkage are the $\mathrm{H}$ bonds having $\mathrm{C} 7-\mathrm{H} 7$ as bifurcated donor to the 04 and $\mathrm{O} 5$ (Fig. 11a), which link 6 molecules of 3 related by the $\overline{3}$ axis along [001] (Fig. 11b). This supramolecular synthon is stacked via Van der Waals interactions parallel to [001] forming infinites channels in a hexagram fashion (Fig. 11b and c). Each channel is surrounded by six other ones due to the space group symmetry forming a very interesting honeycomb-like

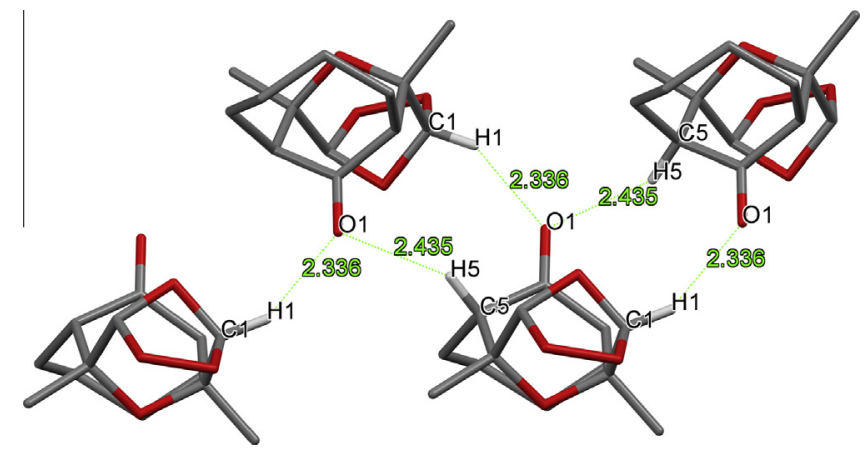

Fig. 9. Partial packing of 9 showing the infinite double-chain parallel to [100] direction stabilized by non-classical H bonds. Some H. . .acceptor separations ( $(\AA)$ are shown. Hydrogen atoms not involved in the $\mathrm{H}$ bonds were hidden for representation clarity.

structure (Fig. 12). Indeed, the highly symmetric hexagonal space group observed for ozonide $\mathbf{3}$ is uncommon considering smallmolecule organic and metal-organic crystal structures. In the Cambridge Structural Database (CSD) [36] only 290 of deposited structures crystallize in $\mathrm{R} \overline{3} \mathrm{~m}$, which represents $\sim 0.04 \%$ of the total number of structures deposited (717895 entries in CSD version 5.35 and update of November 2013, February 2014, and May 2014).

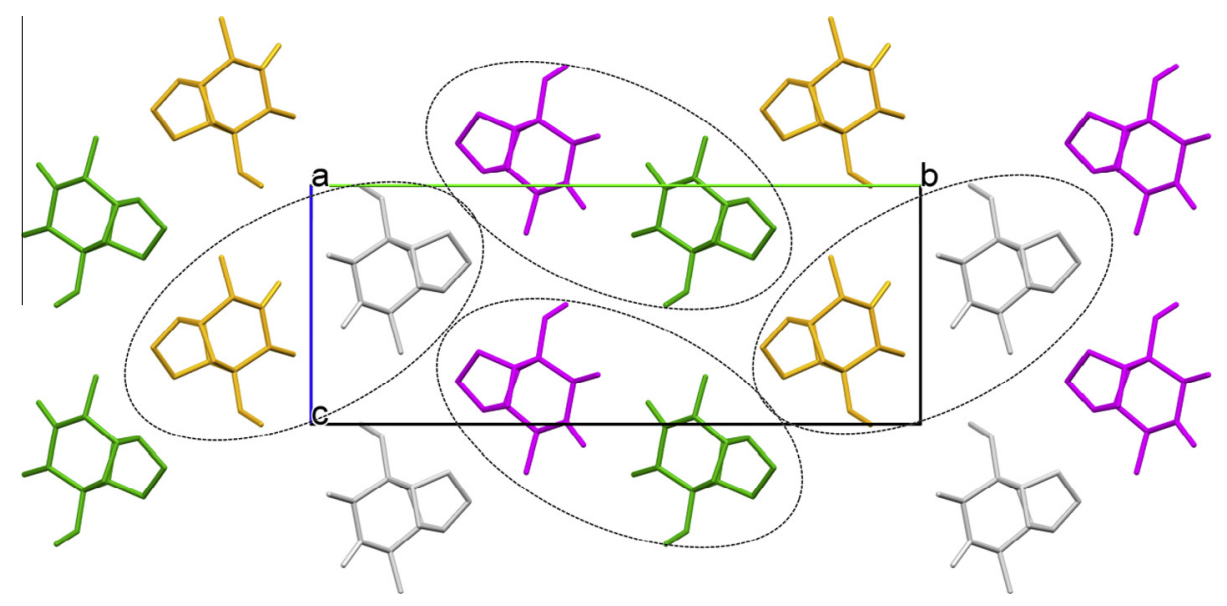

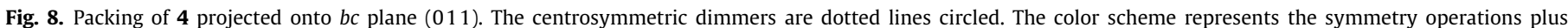

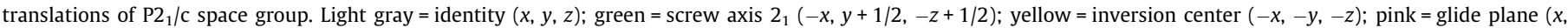
$-y-1 / 2, z-1 / 2)$. (For interpretation of the references to color in this figure legend, the reader is referred to the web version of this article.) 


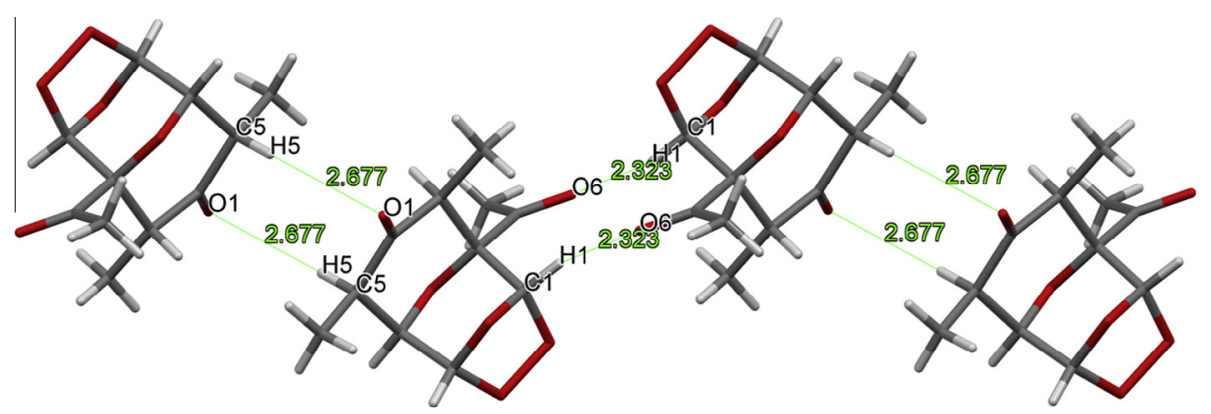

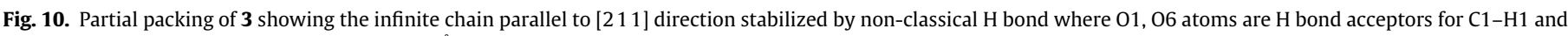
C5-H5 donors. Some H. . .acceptor separations (Å) are also shown.
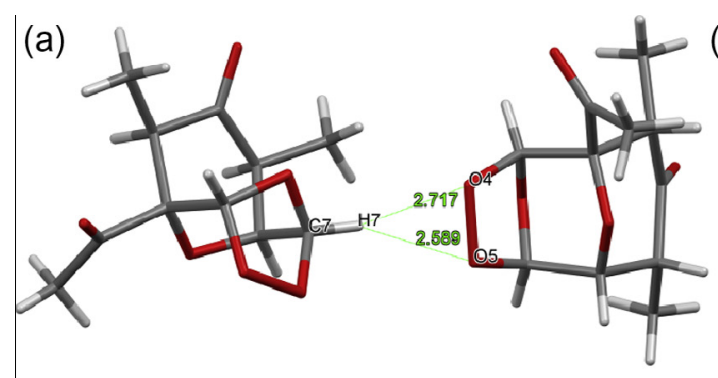

(b)

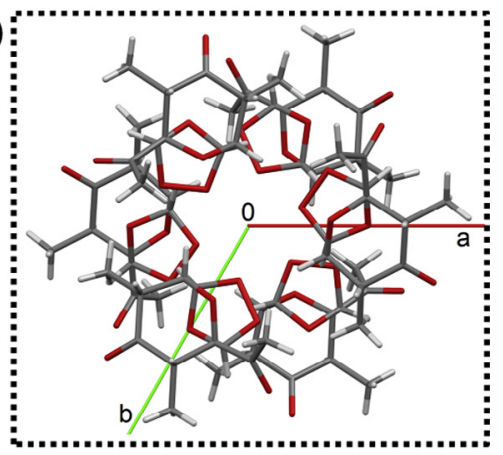

(c)

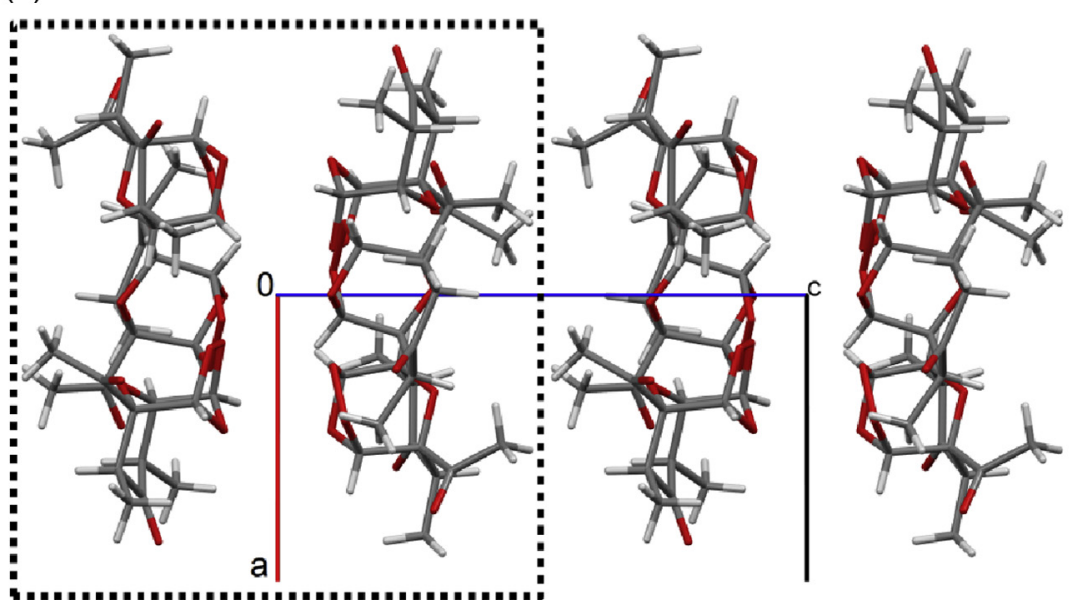

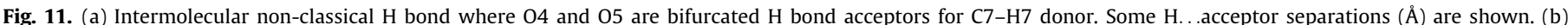

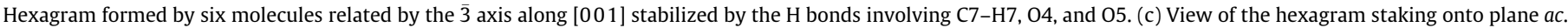

After investigating in detail the structure of several ozonides by $\mathrm{X}$-ray crystallography, and having found some unusual packing systems, we followed such work by some geometries optimization using the semi-empirical PM6 and DFT B3LYP/6-31G(d) methods. Of particular interest is the peroxide bond which is of fundamental importance to the mode of action of the ozonides. In Table 2 a list of the oxygen-oxygen bond lengths of the peroxide bridge, obtained by theoretical calculations and X-ray analysis, is shown.

As can be seen in Table 2, the oxygen-oxygen bond lengths computed with the semi-empirical PM6 method show higher deviation from the experimental values $(2.3-3.8 \%)$ than that obtained with the B3LYP/6-31G(d) approach (0.1-1.8\%). In general, the O$\mathrm{O}$ bond lengths observed in the X-ray analysis (1.484-1.499 $\AA$ ) are more elongated than the standard value of $1.47 \AA$ [22]. In the cyclic structures of compounds (3-9) we expected a shorter bond length due to ring tension.
In Tables 3 and 4 additional values (including the previously discussed) are presented for selected geometrical parameters of the ozonides. B3LYP/6-31G(d) results are comparable with the experimental X-ray data. These data (Tables 3 and 4) shows a quite good correlation between the experimental and calculated values for these cyclic structures [11].

One important parameter is the $\mathrm{H} 6-\mathrm{C} 6-\mathrm{C} 5-\mathrm{H} 5$ (for 3-9, Fig. 13) dihedral angle. From this angle it is possible to assign the stereochemistry of carbons bearing the methyl groups and this information can be obtained by H NMR data [37]. The computed values for the dihedral angles are compared with the experimental X-ray data in Table 5 . As can be observed from such data a better correlation with experimental data were obtained from the DFT calculations. Also, the computed values for the coupling constant $J$ are in good agreement with the experimental data obtained by H NMR. 


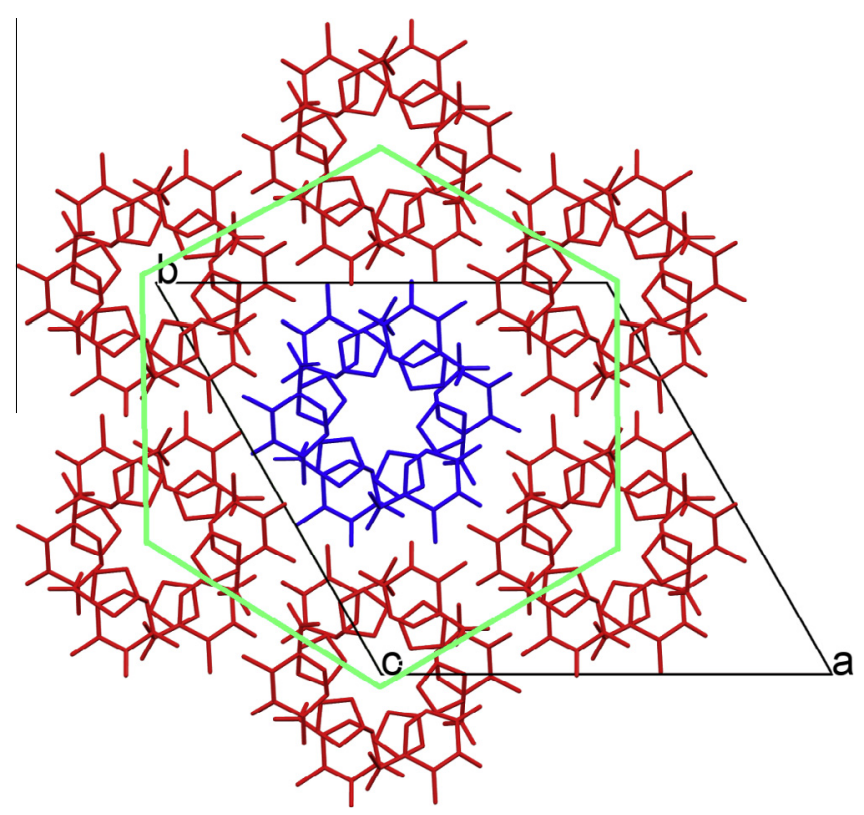

Fig. 12. View of the hexagram stacking onto plane $a b$ highlighting the honeycomblike structure formed. Hydrogen atoms were hidden for representation clarity.

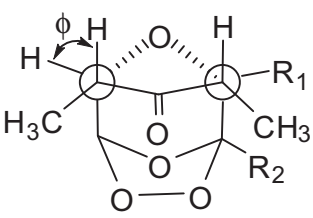

3-7

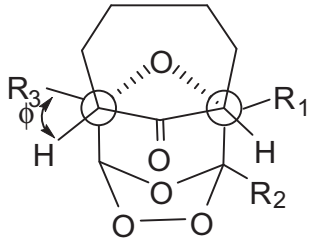

8-9
Fig. 13. Tridimensional structures of compounds 3-9 $\left(\mathrm{R}_{1}=\mathrm{COCH}_{3}, \mathrm{CH}_{2} \mathrm{CH}_{3}, \mathrm{CH}_{3}\right.$; $\left.\mathrm{R}_{2}=\mathrm{H},(\mathrm{CO}) \mathrm{OCH}_{3}, \mathrm{CH}_{2} \mathrm{OH}, \mathrm{CH}_{2} \mathrm{OCH}_{3} ; \mathrm{R}_{3}=\mathrm{H}, \mathrm{CH}_{3}\right)$ showing the dihedral angle $(\phi)$ H6-C6-C5.

\section{Conclusion}

A series of new stable ozonides were prepared in our continuous efforts to find new phytotoxic molecules. In this work the structure of seven ozonides were studied through X-ray diffraction and also by semi-empirical (PM6) and density functional theory methods (B3LYP). From the X-rays analyses we found that five ozonides (4-8) crystallize in the monoclinic crystal system with $\mathrm{P} 2_{1} / \mathrm{c}$ space group as racemic crystal. Compound $\mathbf{9}$ is the unique enantiopure crystal found in this series. The most unusual result was obtained for compound $\mathbf{3}$ that crystallize in the centrosymmetric space group $\mathrm{R} \overline{3} \mathrm{~m}$, which represents $\sim 0.04 \%$ of the total number of structures deposited in the Cambridge Crystallographic Data Centre. The results from geometry optimizations using the functional base B3LYP/6-31G(d) approach are in close agreement with the experimental data obtained by X-ray and also by H NMR.

\section{Acknowledgments}

We thank Conselho Nacional de Desenvolvimento Científico e Tecnológico (CNPq) and Fundação de Amparo à Pesquisa do Estado de Minas Gerais (FAPEMIG) for financial support and research fellowships (ACD, AJD, JWMC, LCAB). The authors express sincere thanks to IFSC-USP for the X-ray facilities.

\section{Appendix A. Supplementary material}

Crystallographic data for the structural analysis of the compounds discussed here have been deposited at the Cambridge Crystallographic Data Centre, 12 Union Road, Cambridge CB2 1EZ, UK, and are available on request quoting the deposition numbers CCDC1016944, 1016932 1016945, 1016943, 1016946, 1016947, and 1016942 for $\mathbf{3 , 4 , 5 , 6 , 7 , 8}$, and 9 respectively. Supplementary data associated with this article can be found, in the online version, at http://dx.doi.org/10.1016/j.molstruc.2014.10.082.

\section{References}

[1] M.W. Walter, Nat. Prod. Rep. 19 (2002) 278-291.

[2] O.F. Hüter, Phytochem. Rev. 10 (2011) 185-194.

[3] S.O. Duke, J.G. Romagni, F.E. Dayan, Crop Prot. 19 (2000) 583-589.

[4] C.L. Cantrell, F.E. Dayan, S.O. Duke, J. Nat. Prod. 75 (2012) 1231-1242.

[5] F.E. Dayan, D.K. Owens, S.O. Duke, Pest Manage. Sci. 68 (2012) 519-528.

[6] P.K. Chen, G.R. Leather, J. Chem. Ecol. 16 (1990) 1867-1876.

[7] S.O. Duke, K.C. Vaughin, E.M. Croom Jr., H.N. Elsohly, Weed Sci. 35 (1987) 499505.

[8] F.E. Dayan, A. Hernández, S.N. Allen, R.M. Moraes, J.A. Vroman, M.A. Avery, S.O. Duke, Phytochemistry 50 (1999) 607-6014.

[9] R.C. Paramanik, B.K. Chikkaswamy, D.G. Roy, A. Paramanik, V. Kumar, J. Phytol. Res. 21 (2008) 11-18.

[10] C.W. Jefford, Drug Discov. Today 12 (2007) 487-495.

[11] A.F.C. Alcântara, D. Piló-Veloso, W.B. De Almeida, C.R.A. Maltha, L.C.A. Barbosa, J. Mol. Struct. 791 (2006) 180-185.

[12] R.R. Teixeira, L.C.A. Barbosa, J.O. Santana, D. Piló-Veloso, J. Ellena, A.C Doriguetto, M.G.B. Drew, F.M.D. Ismail, J. Mol. Struct. 837 (2007) 197-205.

[13] L.C.A. Barbosa, A.V. Costa, A.J. Demuner, A.A. Silva, J. Agric. Food Chem. 47 (2000) 4807-4814.

[14] L.C.A. Barbosa, E.S. Alvarenga, A.J. Demuner, R. Figueiredo, A.A. Silva, Pest Manage. Sci. 59 (2003) 1043-1051.

[15] L.C.A. Barbosa, U.A. Pereira, R.R. Teixeira, C.R.A. Maltha, S.A. Fernandes, G. Forlani, J. Agric. Food Chem. 56 (2008) 9434-9440.

[16] L.C.A. Barbosa, C.R.A. Maltha, R.C. Cusati, R.R. Teixeira, F.F. Rodrigues, A.A. Silva, M.G.B. Drew, F.M.D. Ismail, J. Agric. Food Chem. 57 (2009) 10107-10115.

[17] L.C.A. Barbosa, D. Cutler, J. Mann, M.J. Crabbe, G.C. Kirby, D.C. Warhurst, J. Chem. Soc. Perkin Trans. I (1992) 3251-3252.

[18] L.C.A. Barbosa, D. Cutler, J. Mann, M.J. Crabbe, G.C. Kirby, D.C. Warhurst, J. Chem. Soc. Perkin Trans. I (1996) 1101-1105.

[19] J. Kula, Chem. Health Saf. 6 (1999) 21-22.

[20] S.G.V. Ornum, R.M. Champeau, R. Pariza, Chem. Rev. 106 (2006) 2990-3001.

[21] W.J. Cummins, M.G.B. Drew, J. Mann, E.B. Walsh, J. Chem. Soc. Perkin Trans. 1 (1983) 167-171.

[22] K. Griesbaum, A. Frank, K.J. McCullough, Eur. J. Org. Chem. 8 (2006) 19781980.

[23] Nonius, Collect. Nonius BV, Delft, The Netherlands, 1999.

[24] Z. Otwinowski, W. Minor, Methods in enzymology, in: C.W. Carter Jr., R.M. Sweet (Eds.), Macromolecular Crystallography, Part A, vol. 276, Academic Press, New York, 1997, pp. 307-326.

[25] G.M. Sheldrick, Acta Crystallogr. A A64 (2008) 112-122.

[26] L.J. Farrugia, J. Appl. Crystallogr. 45 (2012) 849-854.

[27] L.J. Farrugia, J. Appl. Crystallogr. 30 (1997) 565-569.

[28] C.F. Macrae, P.R. Edgington, P. McCabe, E. Pidcock, G.P. Shields, R. Taylor, M. Towler, J. van de Streek, J. Appl. Crystallogr. 39 (2006) 453-457.

[29] Spartan '06, Wavefunction Inc., Irvine, CA, USA.

[30] P.J. Stephens, F.J. Devlin, C.F. Chabalowski, M.J. Frisch, J. Phys. Chem. 98 (1994) $11623-11627$.

[31] M.M. Francl, W.J. Pietro, W.J. Hehre, J.S. Binkley, M.S. Gordon, D.J. DeFrees, J.A. Pople, J. Chem. Phys. 77 (1982) 3654-3665.

[32] Gaussian 09, Gaussian Inc, Wallingford CT, 2009.

[33] M. Cianci, J.R. Helliwell, M. Helliwell, V. Kaucic, N.Z. Logar, G. Mali, N.N. Tusar, Crystallogr. Rev. 11 (2005) 245-335.

[34] J. Bernstein, R.E. Davis, L. Shimoni, N.L. Chang, Angew. Chem., Int. Ed. Engl. 34 (1995) 1555-1573.

[35] A. Allerhand, P. von, R. Schleyer, J. Am. Chem. Soc. 85 (1963) 1715-1723.

[36] F.H. Allen, Acta Crystallogr. B 58 (2002) 380-388.

[37] H.M.R. Hoffmann, R. Henning, O.R. Lalko, Angew. Chem., Int. Ed. Engl. 12 (1973) 819-835. 